\title{
A low perfusion rate microreactor for continuous monitoring of enzyme characteristics: application to glucose oxidase
}

\author{
G. A. Posthuma-Trumpie $\cdot$ K. Venema $\cdot$ \\ W. J. H. van Berkel • J. Korf
}

Received: 21 June 2007 /Revised: 29 August 2007 / Accepted: 31 August 2007 / Published online: 2 October 2007

(C) Springer-Verlag 2007

\begin{abstract}
This report describes a versatile and robust microreactor for bioactive proteins physically immobilized on a polyether sulfone filter. The potential of the reactor is illustrated with glucose oxidase immobilized on a filter with a cut-off value of $30 \mathrm{kDa}$. A flow-injection system was used to deliver the reactants and the device was linked online to an electrochemical detector. The microreactor was used for on-line preparation of apoglucose oxidase in strong acid and its subsequent reactivation with flavin adenine dinucleotide. In addition we describe a miniaturized version of the microreactor used to assess several characteristics of femtomole to attomole amounts of glucose oxidase. A low negative potential over the electrodes was used when ferrocene was the mediator in combination with horseradish peroxidase, ensuring the absence of oxidation of electroactive compounds in biological fluids. A low backpressure at very low flow rates is an advantage, which increases the sensitivity. A variety of further applications of the microreactor are suggested.
\end{abstract}

G. A. Posthuma-Trumpie $\cdot$ K. Venema $\cdot$ J. Korf

University of Groningen,

University Medical Centre Groningen (UMCG),

Department Psychiatry, Hanzeplein 1,

9713 EZ Groningen, The Netherlands

W. J. H. van Berkel

Wageningen University and Research Centre,

Wageningen University, Laboratory of Biochemistry,

Dreijenlaan 3, 6703 HA Wageningen, The Netherlands

Present address:

G. A. Posthuma-Trumpie ( $\square)$

Wageningen University and Research Centre,

Agrotechnology and Food Sciences Group of Wageningen UR,

P.O. Box 17, 6700 AA Wageningen, The Netherlands

e-mail: truus.posthuma@wur.nl
Keywords Apoglucose oxidase · Deflavination · Enzyme reactor - Flavin adenine dinucleotide .

Glucose oxidase

\section{Introduction}

Conventionally, characterizing enzyme properties in terms of kinetics, conversion rate, and substrate specificity requires substantial amounts of pure enzyme. We aim to develop a versatile and robust microreactor to monitor online the activity of small amounts of enzymes, and that can be used under harsh conditions if required, for instance, to prepare modified forms of glucose oxidase (GOx) in which the flavin adenine dinucleotide (FAD) cofactor has been replaced by artificial flavins. GOx uses $\beta$-D-(+)-glucose with high specificity as substrate, converting it to gluconolactone and $\mathrm{H}_{2} \mathrm{O}_{2}$. Preparation of apoGOx with low residual activity requires partial unfolding of the protein under strongly acidic conditions followed by removal of the flavin by size-exclusion chromatography [1]. The activity of the enzyme can be restored by applying a solution of FAD or FAD analogues [1-4].

Enzyme reactors can be created by covalent immobilization $[5,6]$. Another option is to co-polymerise the enzyme in a flow system, trapping the enzyme in a polymer matrix $[7,8]$. With these approaches assessment of enzyme properties, inhibitor screening [7], or conversion rates of stereoselective or enantiomeric substrates $[9,10]$ have been reported. Although convenient, covalent attachment and copolymerisation require substantial amounts of protein to obtain a good response [11]. Upon immobilization, enzyme characteristics are often altered and enzyme activity may be lost. Especially when rare or expensive enzymes have to be used, it would be beneficial to have a system that uses far 
less enzyme, does not use chemical immobilization, and is easy to handle.

We propose a device where the enzyme is confined in a small space on top of one filter or between two filters and continuously perfused. The device, based on our previously described biosensor technique [12], is robust, easy to handle, and loss of activity and consumption of enzyme are kept to a minimum. With this device we were able to prepare apoGOx on-line by retaining GOx on a single polyether sulfone (PES) filter using acid treatment. Restoration of the enzyme activity was achieved in the same system using a solution of FAD. Furthermore, we were able to miniaturize the microreactor, using less enzyme, and increase the sensitivity of the system using a combination of ferrocene and horseradish peroxidase (HRP) as a mediator for electrochemical detection.

\section{Experimental}

Materials

GOx from Aspergillus niger (EC 1.1.3.4, grade 1) and horseradish peroxidase (HRP; EC 1.11.1.7, grade 1) were obtained from Roche (Almere, The Netherlands). Ferrocene carbolic acid was from Lancaster Chemicals (Lancaster Synthetics UK, Morecambe, Lancs, UK). Other chemicals were of pro analysis quality and purchased from Merck (Amsterdam, The Netherlands). Double quartz-distilled water was used for all aqueous solutions. Before and after acid treatment, the running buffer (a) of the microreactor was $0.15 \mathrm{~mol} \mathrm{~L}^{-1}$ sodium phosphate, $\mathrm{pH} 7.0$, containing $1 \mathrm{mmol} \mathrm{L}^{-1} \mathrm{NaCl}$ and $0.1 \%$ Kathon GC (Rohm and Haas, Croydon, Surrey, UK). Glucose solution $\left(50 \mathrm{mmol} \mathrm{L}^{-1}\right)$ prepared in running buffer was left to stand for several hours to reach mutarotational equilibrium. For electrochemical detection of GOx in combination with HRP, the running buffer (b) also contained $0.5 \mathrm{mmol} \mathrm{L}^{-1}$ ferrocene carbolic acid.

\section{Design of the microreactors}

The overall design of the microreactors is shown in Fig. 1. They were micro machined from Delrin by the instrumental workshop of Groningen University. For preparation of apoGOx and reconstitution of GOx activity, a microreactor as described in Ref. [12] was used. In contrast to the original device, only one PES filter with a cut-off value of $30 \mathrm{kDa}$ (Sartorius, Göttingen, Germany) and punched to a diameter of $13 \mathrm{~mm}$, was used. Performance studies were done with our miniaturized design. The dimensions of the miniaturized microreactor were: outer length $3 \mathrm{~cm}$, outer diameter $1.5 \mathrm{~cm}$. A PES membrane filter was punched to a diameter of $4 \mathrm{~mm}$ and placed in the microreactor (effective diameter $3 \mathrm{~mm}$, effective volume $1 \mu \mathrm{L}$ ) and connected between the injection
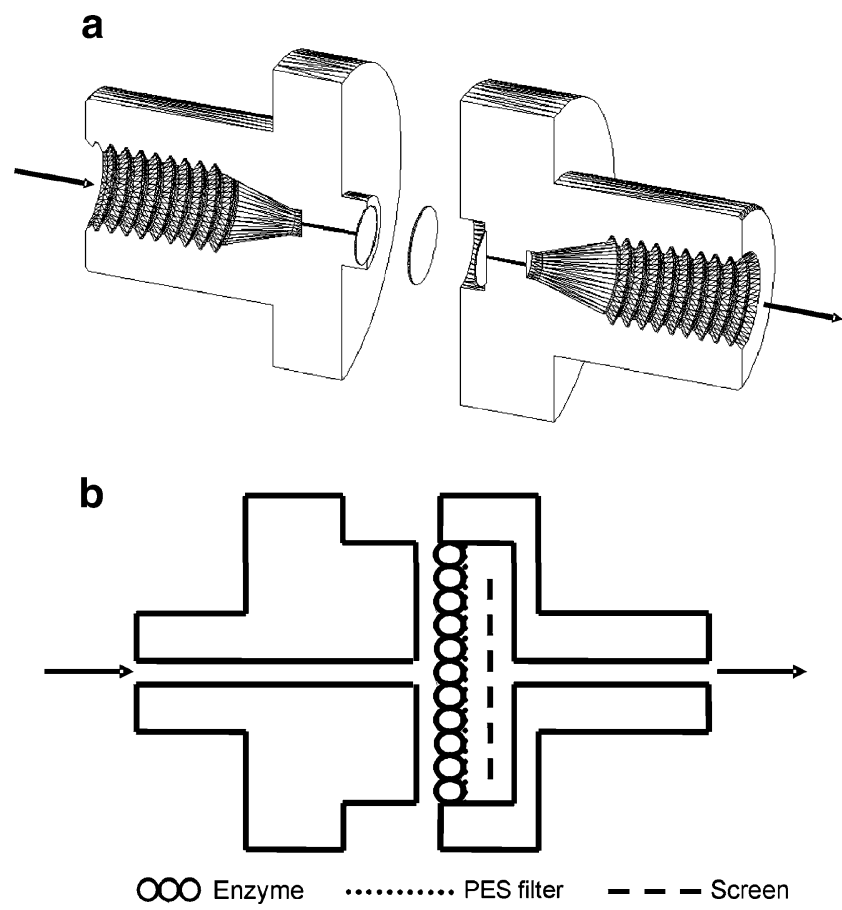

Fig. 1 Schematic design of the reaction compartment of the microreactor. (a) sketch; (b) schematic diagram. Shown here is the microreactor with one PES ultrafilter which is then connected to the flow system using FST and finger-tight fittings. The mesh screen is used to support the ultrafilter

valve and the detector with fused-silica tubing (FST) $(150 \mu \mathrm{m}$ OD, $50 \mu \mathrm{m}$ ID) (Polymicro Technologies, Phoenix, AZ, USA) pinched off in Teflon tubing 1/16 inch OD and $170 \mu \mathrm{m}$ ID (Aurora Borealis Control, Schoonebeek, The Netherlands) with use of finger-tight fittings, to avoid high dead volumes.

Set-up of the system

The perfusates of the microreactor were introduced into a flowinjection system and monitored electrochemically (VT-03 electrochemical flow cell and Decade Digital Electrochemical Amperometric Detector; Antec Leyden, Zoeterwoude, The Netherlands), essentially as previously described [13-15]. For the preparation of apoGOx and subsequent reconstitution of the holoenzyme a voltage of $+0.5 \mathrm{~V}$ was applied between the working and reference electrodes.

\section{GOx/HRP activity monitoring}

For flows $>1 \mu \mathrm{L} \mathrm{min}{ }^{-1}$, a LC10ADvp solvent-delivery pump (Shimadzu Corporation, Kyoto, Japan) was used; for flows

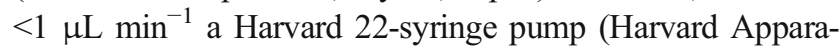
tus, Holliston, MA, USA) was used. A voltage of $-150 \mathrm{mV}$ was applied between the working (glassy carbon) and reference $(\mathrm{Ag} / \mathrm{AgCl})$ electrodes. The injection valve (Vici Cheminert $\mathrm{C} 4$, Valco Instruments, Houston, TX, USA) was equipped with a $20 \mathrm{~nL}$ internal loop; injection cycles were 
designed using software incorporated in the Decade system, which also thermostatically controlled the reaction temperature at $37^{\circ} \mathrm{C}$. The current was registered using a flatbed recorder type BD41 (Kipp \& Zonen, Delft, The Netherlands) and/or the signal was integrated using Chromeleon Software (Dionex Corporation, Sunnyvale, CA, USA) on a PC using an RS232 interface. After the filter was installed in the system, it was left to equilibrate to a flow of $50 \mathrm{~nL} \mathrm{m^{-1 }}$. Glucose solution injection was sequenced to load/inject 2/ $3 \mathrm{~min}$ (cycle time $5 \mathrm{~min}$ ) and repeated until a stable baseline was obtained.

Preparation of apoGOx and restoration of the enzyme activity

Preparation of apoGOx was essentially the same as described in Ref. [16], with a solution of $0.1 \mathrm{~mol} \mathrm{~L}^{-1}$ glycine, $0.1 \mathrm{~mol} \mathrm{~L}^{-1}$ $\mathrm{NaCl}$, and $0.1 \mathrm{~mol} \mathrm{~L}^{-1} \mathrm{HCl}, \mathrm{pH} 1.5$ mixed with glycerol to a final concentration of glycerol of $30 \%(v / v)$, cooled in ice. This solution was applied to the GOx containing reactor. In detail, a $10 \mu \mathrm{L}$ solution of $100 \mathrm{mg} \mathrm{mL}^{-1} \mathrm{GOx}\left(625 \mu \mathrm{mol} \mathrm{L}^{-1}\right)$ was pipetted on to the microreactor's PES filter, which was thus loaded with $6.25 \mathrm{nmol}$. After stabilisation of the signal, the initial enzyme activity was determined $(=100 \%)$. The reactor was detached from the detector. The detached reactor was cooled in ice, and perfused with the cooled acidic glycerol solution at a rate of $25 \mu \mathrm{L} \mathrm{min}{ }^{-1}$ for $15 \mathrm{~min}$. After application of running buffer (a) until the effluent was $\mathrm{pH} 7$, the reactor was taken out of the flow system, re-attached to the detector cell, and the residual activity of the apoGOx was measured in buffer system (a) with a flow of $25 \mu \mathrm{L} \mathrm{min}{ }^{-1}$.

After the reactor was released from the flow system, ca $150 \mu \mathrm{L}$ of an FAD solution $\left(3.4 \mathrm{mmol} \mathrm{L}^{-1}\right)$ in $0.15 \mathrm{~mol} \mathrm{~L}^{-1}$ sodium phosphate, $\mathrm{pH} 7.0$, at room temperature, was applied manually during ca $15 \mathrm{~min}$, except for timedependent tests. Afterwards, the reactor was re-attached to the detector cell and the restored activity of the holoenzyme was measured as described above.

Determination of several characteristics of the miniaturized enzyme reactor

Increasing amounts of GOx in running buffer (b) (range 625 amol to 625 pmol) were injected into the system, providing the amount of GOx retained on the membrane. After equilibration, a sequence of load/inject of the glucose solution was applied. Subsequently, a solution of HRP in running buffer (b) was injected into the system providing $0.68 \mathrm{pmol}(30 \mathrm{ng})$ of HRP. After equilibration the sequence of load/inject of glucose was repeated. The efficiency of conversion at the electrode was calculated according to Eq. (1):

$\%$ conversion $=\frac{\sqrt{(2 \pi)} h \sigma 100 \%}{I c n F}$ where $h=$ peak height $(\mathrm{pA}), \sigma=$ peak width at $60.7 \%(\mathrm{~s}), I=$ injection volume $(\mu \mathrm{L}), c=$ concentration $\left(\mu \mathrm{mol} \mathrm{L} \mathrm{L}^{-1}\right), n=$ number of electrons, $F=96485$ (Faraday's constant, C $\left.\mathrm{mol}^{-1}\right)$ and $\sqrt{ }(2 \pi) \mathrm{h} \sigma$ is peak area (C)

In Eq. (1) the charge that is transferred to the electrode (area under the curve) is related to the real charge that is available in the reaction, e.g. the concentration of the substrate, the number of electrons involved, and Faraday's constant.

\section{Results}

Preparation of apoGOx and restoration of the enzyme activity

We followed the response to glucose, the residual enzyme activity of apoGOx after acid treatment, and restoration of the enzyme activity after application of a solution of FAD. After acid treatment, negligible activity of apoGOx was observed. Application of the FAD solution restored the enzyme activity. The time dependency of enzyme activity restoration is shown in Fig. 2, composed of individual data from five apoGOx preparations. This time dependency of the reactivation is in accordance with Eq. (2).

$\mathrm{f}(\mathrm{t})=1-\exp (-\mathrm{kt})$

where $k=0.035 \mathrm{~min}^{-1}$ and $t$ is the reaction time (min).

Approximately $80 \%$ of the enzyme activity was restored within $60 \mathrm{~min}$, which is above average compared to other procedures $[1,2]$.

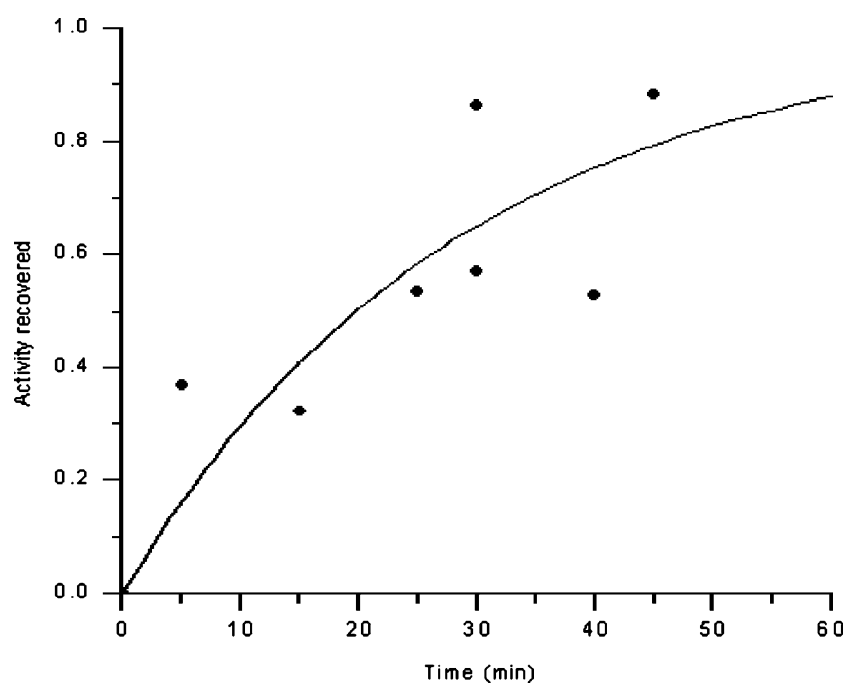

Fig. 2 Restoration of apoGOx activity: circles, observed relative reactivation with $\mathrm{FAD}$; solid line, fitting according to the equation $f(t)=$ $1-\exp (-0.035 t)$ 


\section{Performance}

Several properties of the system were investigated. These included backpressure of the reactor at various protein loads, its stability and reproducibility, the efficiency at the electrode, system sensitivity, and ease of handling. The relationship of backpressure to the flow and the amount of protein retained on the filter are depicted in Figs. $3 \mathrm{a}$ and $3 \mathrm{~b}$. The level of the backpressure is acceptable with these flows and these amounts of protein. The stability and reproducibility of the system, as tested with 625 fmol GOx on a series of glucose injections, showed an intra-assay standard deviation of less than $3 \%$. The efficiency of the reaction is inversely proportional to the amount of protein on the filter. The sensitivity of the set-up was determined by retaining

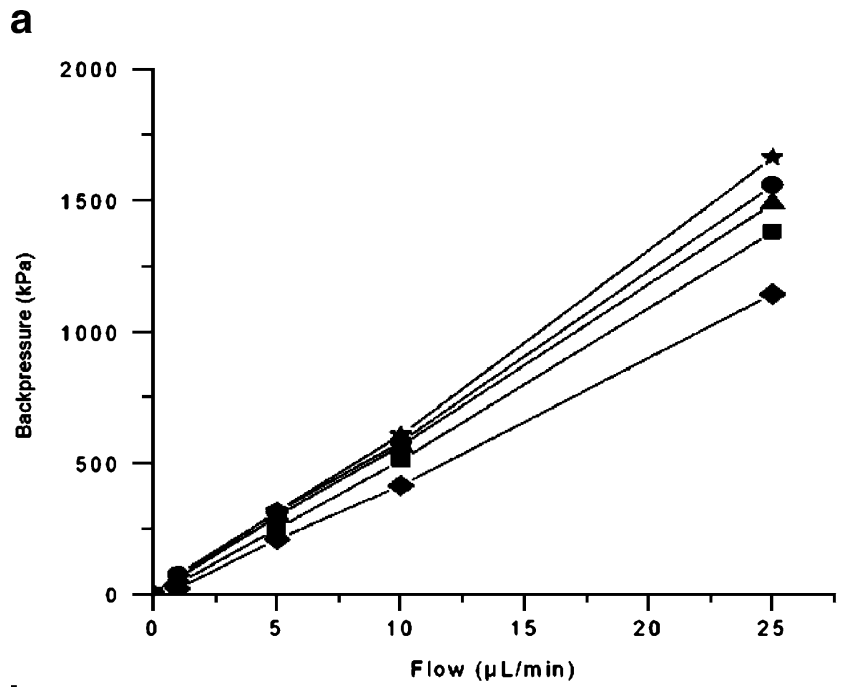

b

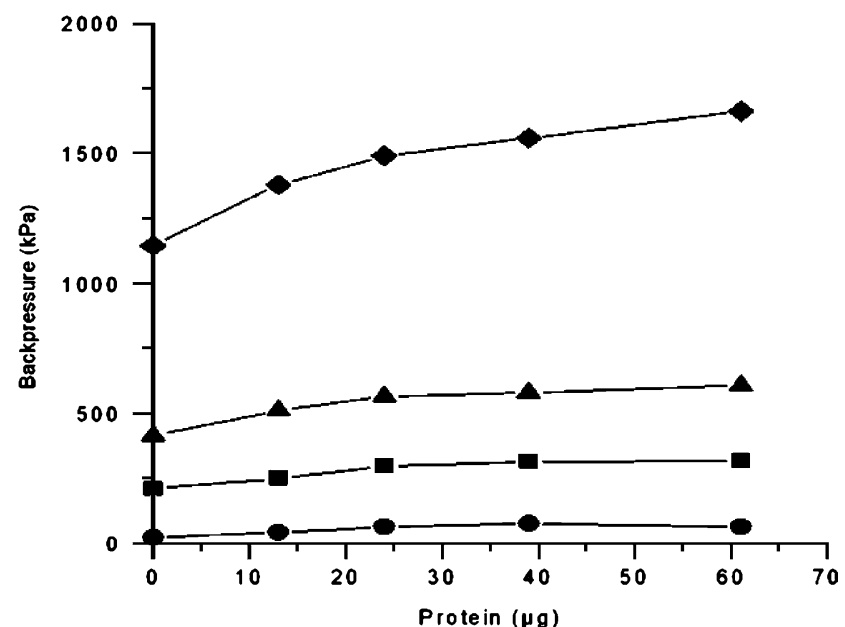

Fig. 3 System backpressure. (a) Backpressure in relation to the flow at various protein loadings: diamonds, $0 \mu \mathrm{g}$; squares, $13 \mu \mathrm{g}$; triangles, $24 \mu \mathrm{g}$; circles, $39 \mu \mathrm{g}$; stars, $61 \mu \mathrm{g}$ GOx. (b) Backpressure in relation to the amount of protein retained on the filter at various flow rates: circles $1 \mu \mathrm{L} \mathrm{min}{ }^{-1}$; squares, $5 \mu \mathrm{L} \mathrm{min}{ }^{-1}$; triangles, $10 \mu \mathrm{L} \mathrm{min}{ }^{-1}$; diamonds, $25 \mu \mathrm{L} \mathrm{min}$ min $^{-1}$
Table 1 Measured detector signal and relative conversion of glucose in relation to the amount of enzyme retained on the filter in the miniaturized microreactor. Indicated are the amounts of GOx (in fmol) on the PES filter and the signals of the detector (in $\mathrm{nA}$ ) indicating the amount of converted glucose, calculated as described in the method section

\begin{tabular}{cll}
\hline Protein (GOx) on the filter (fmol) & Signal (nA) & Conversion (\%) \\
\hline 0.0625 & 0.016 & 0.04 \\
0.625 & 0.028 & 0.006 \\
6.25 & 0.051 & 0.001 \\
625 & 0.53 & 0.0001 \\
625000 & 2.4 & 0.0000006
\end{tabular}

various amounts of GOx, ranging from 62.5 amol to $625 \mathrm{pmol}$ on the ultrafilter, and testing the response. A measurable and reproducible response was obtained, even with the lowest amounts of enzyme tested (Table 1). One load of enzyme in the microreactor can be used at least 10 times and the system can be regenerated simply by replacing the filter and injection of a fresh aliquot of protein solution.

\section{Conclusions}

The low perfusion rate microreactor is suitable for the new application described here-preparation of minute amounts of apoGOx and reconstitution of enzyme activity with a solution of FAD. In comparison to the conventional preparation of apoGOx using size-exclusion chromatography $[1,2,16]$, this device requires neither complicated handling nor expensive materials and equipment. The enzyme is simply retained on the PES ultrafilter.

A scale-up of the microreactor can easily be performed, allowing the preparation of larger amounts of apoGOx to be used, for example, in studies with modified FAD [2-4] or as the basis of a biosensor with which a wide variety of analytes can be detected [1]. The combination with immunological principles allows the analysis of small molecules when no specific enzyme is available, combining molecular recognition with enzyme enhancement of the signal. The sensitivity is improved even more by using electrochemical detection.

Low perfusion rate microreactors may facilitate the study of enzymatic properties and modifications, including substrate inhibition, competitive and non-competitive inhibition, and allosteric activation. Because of the mild fixation conditions, they may enable investigation of receptor activity also. An advantage of the microreactor presented here is the small amount of protein required, thus allowing the use of expensive and rare enzymes. Applications using related devices, e.g. Refs. [7, 10, 17] usually require micrograms to 
milligrams of protein. Glucose sensors using glucose oxidase or glucose dehydrogenase have also been developed for clinical use. One example of such an application uses a volume of $300 \mathrm{~nL}$ blood for glucose measurements in diabetics [18]. Such reactors still use larger volumes as compared to the $20 \mathrm{~nL}$ we used here. Although we used electrochemical detection, other modes of detection including capillary electrophoresis, fluorescence, or chemiluminescence, are possible. In addition, with the current interest in proteomics, applications can be found where minute amounts of protein can be digested reproducibly and analysed directly by LC-MS-MS [19-21].

Acknowledgements The study was supported by the Dutch Technology Foundation (STW), grant number GPG 6038.

\section{References}

1. Morris DL, Buckler RT (1983) In: Langone JJ, Van Vunakis H (eds) Methods in enzymology, vol 92. Academic Press, New York, pp 413-425

2. Posthuma-Trumpie GA, van den Berg WAM, van de Wiel DFM, Schaaper WMM, Korf J, van Berkel WJH (2007) BBA-Proteins Proteom 1774:803-812

3. Sanner C, Macheroux P, Rueterjans H, Mueller F, Bacher A (1991) Eur J Biochem 196:663-672
4. Willner I, Heleg-Shabtai V, Blonder R, Katz E, Tao G, Buckmann AF, Heller A (1996) J Am Chem Soc 118:10321-10322

5. Bartolini M, Andrisano V, Wainer IW (2003) J Chromatogr A 987:331-340

6. Vojinovic V, Calado CR, Silva AI, Mateus M, Cabral JMS, Fonseca LP (2005) Biosens Bioelectron 20:1955-1961

7. Hodgson RJ, Besanger TR, Brook MA, Brennan JD (2005) Anal Chem 77:7512-7519

8. Mersal GAM, Bilitewski U (2005) Electrophoresis 26:2303-2312

9. Sotolongo V, Johnson DV, Wahnon D, Wainer IW (1999) Chirality 11:39-45

10. Bertucci C, Petri A, Felix G, Perini B, Salvadori P (1999) Tetrahedron Asymmetry 10:4455-4462

11. Hefti MH, Vervoort J, van Berkel WJH (2003) Eur J Biochem 270:4227-4242

12. Flentge F, Venema K, Koch T, Korf J (1992) Anal Biochem 204:305-310

13. Leegsma-Vogt G, Janle E, Ash SR, Venema K, Korf J (2003) Life Sci 73:2005-2018

14. Leegsma-Vogt G, Rhemrev-Boom M, M., Tiessen R, G., Venema K, Korf J (2004) Bio-Med Mater Eng 14:455

15. Leegsma-Vogt G, Venema K, Brouwer N, Gramsbergen JB, Copray S, Korf J (2004) Anal Chem 76:5431-5435

16. Heiss C, Weller MG, Niessner R (1999) Anal Chim Acta 396:309-316

17. Cardoso CL, Lima VV, Zottis A, Oliva G, Andricopulo AD, Wainer IW, Moaddel R, Cass QB (2006) J Chromatogr A 1120:151-157

18. Feldman B, McGarraugh G, Heller A, Bohannon N, Skyler J, DeLeeuw E, Clarke D (2000) Diabetes Technol Ther 2:221-229

19. Duan J, Liang Z, Yang C, Zhang J, Zhang L, Zhang W, Zhang Y (2005) Proteomics 6:412-419

20. Krenková J, Bilková Z, Foret F (2005) J Sep Sci 28:1675-1684

21. Aebersold R, Mann M (2003) Nature 422:198 